\title{
Comparación de la viabilidad y crecimiento en cultivo de células madre adultas obtenidas de tejido adiposo pre y post congelamiento
}

\author{
Comparison of the viability and growth in stem cell culture obtained \\ from adipose tissue (ADAS) pre and post freeze
}

Luz Mabel Ávila Portillo MSc, cPhD ${ }^{1,2}$, Derly Johanna Franco Ruiz ${ }^{1}$, Jenniffer Priscila Avila García MSc ${ }^{1}$, Angela Giselle Riveros Arocha ${ }^{1}$, Sabogal Mauricio MD $^{2}$

\section{Resumen}

Objetivo. Comparar viabilidad, crecimiento en cultivo, fenotipo y diferenciación a linaje osteogénico de ADAS(Adipose-DerivedAdultStem Cells)preypostcongelamiento.Método.SeobtuvieronmuestrasdeTA deindividuossanosquefueronsometidosaliposucción,conposteriordigestiónenzimáticacon ColagenasaI. La fracción vascular estromal (FVE) obtenida fue dividida equitativamente en dos fracciones una de las cuales fue criopreservada y almacenada a $-196^{\circ} \mathrm{C}$ y la otra cultivada hasta pase uno antes de ser criopreservada. Ambas fracciones fueron criopreservadas en cámara de congelamiento automatizada utilizando dos soluciones de congelamiento: (A) Dimetilsulfóxido (DMSO)/Dextrano40/albúmina sérica humana (HSA) y (B) DMSO/HESSICO/HSA, mantenidas 3 meses a $-196^{\circ} \mathrm{C}$ y descongeladas con buffer fosfato salino (PBS)/HSA/HESSICO. Posterior a su descongelamiento fueron sometidas a cultivo, recuento, viabilidad celular, fenotipificación y potencial osteogénico. Resultados. Las células congeladas con la solución crioprotectora DMSO/Dextrano40/ HSA y con un cultivo previo al congelamiento, presentaban porcentajes de viabilidad más altos y alcanzaban confluencia del $80 \%$ en cultivo en menos tiempo. Las muestras expandidas no presentaron diferencias en el fenotipo por citometría de flujo y mostraron diferenciación a linaje osteogénico.

Palabras clave: células madre mesenquimales, tejido adiposo, criopreservación.

\section{Abstract}

Objective. Comparing viability, growth in culture, phenotype and osteogenic lineage differentiation of Adipose-Derived Adult Stem Cells (ADAS) pre and post freezing. Method. Samples were obtained from adipose tissue of healthy individuals who underwent liposuction, with later enzymatic digestion with collagenase I. The stromal vascular fraction (SVF) obtained was divided equally into two fractions one of which was cryopreserved and stored at $-196{ }^{\circ} \mathrm{C}$ and the other one cultivated to passage 1 (P1) before being cryopreserved. Both fractions were cryopreserved in an automated freezing chamber using two freezing solutions: (A) DMSO/Dextran40/HSA and (B) DMSO/HESSICO/HSA kept, both were kept 3 months at $-196^{\circ} \mathrm{C}$ and thawed in PBS/HSA/ HESSICO. After thawing, both were subjected to cultivation, recount, cell viability, phenotyping and osteogenic potential. Results. Cells that were frozen with cryoprotectant solution DMSO/ Dextran40/HSA and a pre-freezing culture exhibited higher viability percentages and reached $80 \%$ culture confluence in less time. Expanded samples showed no differences in the phenotype by flow cytometry and showed differentiation to osteogenic lineage.

Keywords: dipose tissue, cryopreservation, mesenchymal stem cells.

${ }^{1}$ Stem Medicina Regenerativa

${ }^{2}$ Hospital Militar Central

Correspondencia: laboratorio@bancodecelulas.com

Recibido: 09/01/2015 Aceptado: 08/06/2015
LUZ MABEL AVILA PORTILLO HYPERLINK "https://orcid.org/0000-0002-9425-8736"0000-0002-9425-8736 DERLY JOHANNA FRANCO 0000-0003-1200-292X

JENNIFFER AVILA HYPERLINK "http://orcid.org/0000-0001-6980-9201"0000-0001-6980-9201

ANGELA RIVEROS 0000-0003-3228-3685

MAURICIO SABOGAL 0000-0003-3616-8633 


\section{Introducción}

Las células madre (CM) son objeto de estudio como alternativa terapéutica en enfermedades crónico-degenerativas. Por esta razón, la identificación de fuentes celulares diferentes a la médula ósea es motivo de investigación emergente. Los estudios in vitro y ensayos clínicos han demostrado que las CM adultas de tejido adiposo (TA) (ADAS, Adipose-Derived Adult Stem Cells) son una alternativa en medicina regenerativa. De esta manera, la criopreservación de ADAS debe ser optimizada para garantizar almacenamiento seguro y fácil disponibilidad para su utilización a futuro.

De esta forma, la médula ósea ha sido la fuente principal de células madre adultas, sin embargo en los últimos años se ha descubierto que la fracción estromal del tejido adiposo humano contiene una población de células con características de células stem mesenquimales (MSC) capaces de autorrenovarse y diferenciarse. Estas células madre adultas (ADAS, Adipose-Derived Adult Stem Cells) son una alternativa en medicina regenerativa, convirtiendo al tejido adiposo en una fuente importante de MSC (1), ya que además de su fácil extracción en cirugías como la liposucción, permite obtener mayor número de células en comparación con la médula ósea (MO) (2).

Las MSC obtenidas de tejido graso pueden diferenciarse in vitro hacia linaje osteogénico, adipogénico, miogénico y condrogénico, demostrado por varios estudios previos (3-5), así mismo exhiben marcadores de membrana de linaje específico similares a los observados en MSC (CD44+/45$173+/ 90+)$, y pueden ser conservadas a bajas temperaturas durante largos periodos de tiempo, manteniendo todo su potencial hasta el momento de ser reutilizadas en beneficio del paciente (6).

En la actualidad la criopreservación de las células madre de tejido adiposo se realiza mediante el uso de suplementos proteínicos de origen animal como el suero fetal bovino (SFB) y agentes crioprotectores (ACP) intracelulares como el dimetilsulfóxido (DMSO), usado como crioprotector desde su descubrimiento en 1959 (7). Aunque el DMSO es considerado relativamente no tóxico, no obstante el uso clínico de células tratadas con éste suele causar efectos secundarios y reacciones tóxicas. Además se ha demostrado que induce la diferenciación de las células madre a células cardiacas o neuronales cuando se añade al medio de cultivo celular (8).

Es así como el éxito de los protocolos para criopreservación depende en gran medida del conocimiento de las características propias del material biológico que desea conservarse, y la manera en que éstas pueden incidir en el mantenimiento de la viabilidad y funcionalidad después de la congelación, así como a la mejor combinación de ACP, ya que hay agentes penetrantes que protegen a las células de las lesiones producidas por las congelaciones a velocidad lenta, y agentes no penetrantes como en Dextrano40, que ejercen su acción crioprotectora promoviendo la rápida deshidratación celular, y se usan de forma asociada (9).

También se evalúa la posibilidad de incluir en la preparación de soluciones de congelamiento y descongelamiento, los sustitutos del plasma como el HESSICO y expansores plasmáticos análogos, además de la albúmina sérica humana (HSA), ya que sus propiedades coloidales facilitan el transporte a través de la membrana en los procesos de deshidratación e hidratación, semejando su acción terapéutica como sustituto coloidal del volumen plasmático (10).

Se ha experimentado el almacenamiento a largo plazo de los injertos de grasa con técnicas de congelación sencillas. En un estudio los injertos de grasa se congelaron en nitrógeno líquido y fueron almacenados a $-195.8^{\circ} \mathrm{C}$ durante un máximo de 8 días. Los resultados demostraron notable mantenimiento de la actividad metabólica mitocondrial. Sin embargo, un estudio independiente indicó que después de la congelación sencilla, hasta el 92,7\% de la actividad metabólica de los injertos de grasa se pierde, pero la adición de un agente crioprotector conduce a la preservación de hasta el 54\% de la actividad (11). Por lo tanto, es importante desarrollar 
protocolos de criopreservación evaluando la mejor combinación de ACP y teniendo en cuenta las características de cada tipo de célula con el fin de favorecer la viabilidad y funcionalidad celular.

En un esfuerzo para hacer frente a los retos que plantea la criopreservación de ADAS, este estudio examinó el cultivo, recuento, viabilidad celular, fenotipificación y potencial osteogénico de ADAS con dos soluciones de congelamiento. Además, de analizar los beneficios de hacer un cultivo previo al congelamiento de las células.

\section{Materiales y métodos}

Se diseñó un estudio experimental in vitro de riesgo mínimo, teniendo como criterios de selección de los donantes de tejido adiposo una edad mayor a 18 años, sin enfermedades infecto contagiosas y la aceptación de participar en el estudio mediante firma del consentimiento informado. El estudio se dividió en cinco fases: 1 . Obtención de células de tejido adiposo. 2. Criopreservación y descongelamiento. 3. Cultivo celular. 4. Fenotipificación. 5. Diferenciación osteogénica.

\section{Obtención y procesamiento del tejido adiposo}

Se recolectó tejido adiposo que iba a ser descartado, de pacientes que se sometieron a cirugías de liposucción convencional o por ultrasonido (VASER') bajo anestesia general, previa firma de consentimiento informado. Las intervenciones fueron realizadas en la Clínica Sabamec (Bogotá, Colombia) durante los ańos 2011 y 2012.

El procesamiento del tejido adiposo se llevó a cabo en Stem Medicina Regenerativa, dentro de las 24 horas posteriores a la cirugía, empleando la técnica de digestión enzimática para la obtención celular, a partir de 20 gramos de tejido adiposo.

La digestión enzimática se realizó con Colagenasa I $0.075 \%$ (Gibco), agitación constante e incubación a $37^{\circ} \mathrm{C}$ durante 45 minutos. Se centrifugó a 1200 rpm durante 10 minutos para obtener el botón celular de la fracción vascular estromal (FVE), y se filtró mediante membrana de Nylon de $100 \mu \mathrm{m}$. La FVE obtenida fue resuspendida en medio de cultivo de Eagle modificado por Dulbecco bajo en glucosa (DMEM-LG, Sigma) suplementado con 10\% de lisado de plasma rico en plaquetas (LPRP) grupo O, Rh positivo. Se realizó recuento en cámara hemocitométrica de Neubauer y viabilidad celular con azul de tripán, y a su vez fue dividida equitativamente en dos fracciones: la fracción 1 fue criopreservada y almacenada a $-196^{\circ} \mathrm{C}$ y la fracción 2 fue cultivada en DMEM-LG (Sigma), suplementado con 10\% de LPRP grupo O, Rh positivo, hasta pase 1 (confluencia del 80\%), Figura 1.

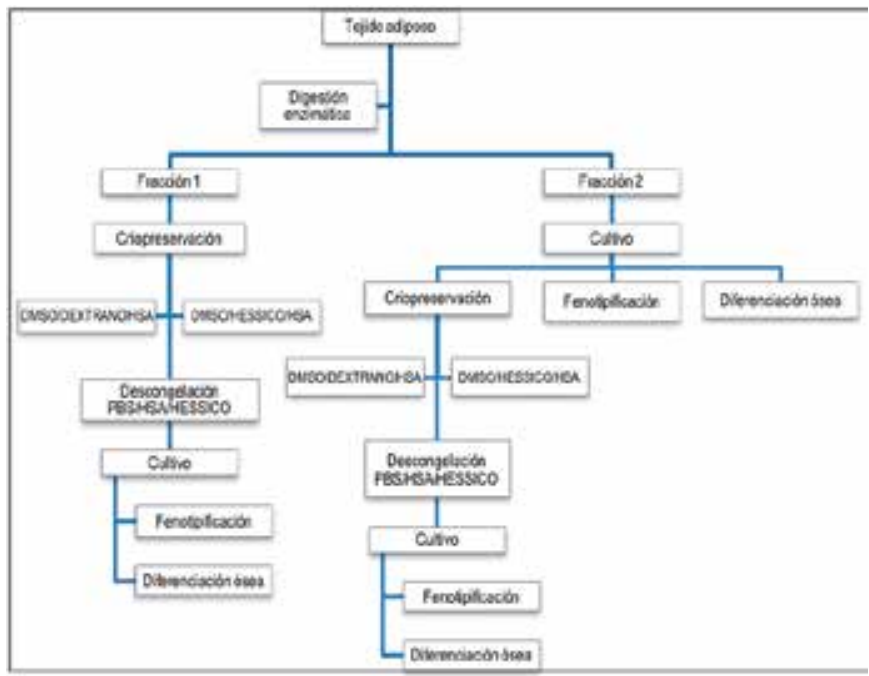

Figura 1. Esquema de la metodología aplicada en el estudio 


\section{Criopreservación}

Para el estudio se evaluó la combinación de los ACP DMSO, Dextrano40 y HESSICO, para formar dos soluciones de congelamiento: (A) DMSO/Dextrano 40 5\%/HSA 5\% y (B) DMSO/HESSICO 5\%/HSA 5\%. Las células fueron contadas y resuspendidas en la solución de congelamiento respectiva a una densidad de $1 \times 10^{6}$ células $/ \mathrm{mL}$ controlando la homogenización de la muestra. El porcentaje de solución utilizada para almacenar y criopreservar las células obtenidas fue de $25 \%$ de solución para el caso A y $20 \%$ para el caso B. En el proceso de congelación se utilizaron criotubos de $2 \mathrm{~mL}$ que fueron llevados a cámara de congelamiento automatizada (Thermo CryoMed Freezer) y luego a tanques de nitrógeno líquido (NL) donde permanecieron durante 3 meses a $-196^{\circ} \mathrm{C}$.

\section{Cultivo celular}

Las células obtenidas fueron cultivadas en cajas de cultivo T-150 $\left(150 \mathrm{~cm}^{2}\right.$, Falcon $)$ con medio de cultivo DMEM-LG (Sigma) suplementado con $10 \%$ de LPRP, $1 \%$ de antibiótico (Penicilina/ Estreptomicina 100X, Gibco) y $0.5 \%$ de Factor de Crecimiento Fibroblástico Básico (bFGF). Se incubaron a $37^{\circ} \mathrm{C}$ en una atmósfera húmeda con $5 \%$ de $\mathrm{CO}_{2}$ durante 24 horas, y tiempo después se realizó el primer cambio de medio. Posteriormente el medio fue cambiado cada 3 días hasta alcanzar confluencia del $80 \%$. La morfología, adherencia y proliferación celular se comprobaron mediante microscopio invertido.

\section{Descongelamiento}

Las células criopreservadas fueron descongeladas usando la solución PBS/HSA/HESSICO. Se realizó recuento celular, viabilidad basada en exclusión por azul de trypan, cultivo, identificación de marcadores de membrana y diferenciación osteogénica.

\section{Fenotipificación}

Las células madre obtenidas de tejido adiposo de primer y segundo pase en $80 \%$ de confluencia fueron disociadas con TrypLE ${ }^{\mathrm{Tm}}$ Select $1 \mathrm{X}$ (GIBCO), llevadas a una concentración de $1 \times 10^{5}$ células e incubadas con los anticuerpos monoclonales conjugados a flourocromos. Se empleó el Kit de Análisis de MSC Humanas (BD Stemflow") que incluye un cóctel positivo (FITC CD90, PerCP-Cy ${ }^{\mathrm{Tm}} 5.5$ CD105 y APC CD73) y un cóctel negativo (PE CD45, PE CD34, PE CD11b, PE CD19 y PE HLA-DR). La identificación de los marcadores de superficie se llevó a cabo en un citómetro de flujo BD FACS Canto II ubicado en los laboratorios de Stem Medicina Regenerativa.

\section{Diferenciación osteogénica}

Para el ensayo de diferenciación se utilizaron células de segundo y tercer pase. En el experimento se evaluó la diferenciación después de 5 semanas de cultivo con medio de diferenciación osteogénica. Las ADAS fueron subcultivadas en platos de 6 pozos (TPP), con DMEM-LG (Sigma). Cuando alcanzaron confluencia del $70 \%$ se cambió el medio por medio de estimulación osteogénica (Mesencult') suplementado con los factores de inducción daxametasona $10^{-8} \mathrm{M}$ (Stem cell Technologies), ácido ascórbico $50 \mu \mathrm{g} / \mathrm{mL}$ (Stem cell Technologies), y $\beta$-glicerol fosfato $3.5 \mathrm{mM}$ (Stem cell Technologies). Como control negativo se utilizaron células cultivadas en DMEM-LG (Sigma).

Las células diferenciadas y las células control se sometieron a dos tinciones: Von Kossa para la identificación de depósitos de calcio y Fosfatasa Alcalina (AP) para la demostración histoquímica de la actividad de esta enzima. Para la tinción de Von Kossa las células fueron lavadas y coloreadas con nitrato de plata al 5\%, exponiéndolas a luz UV durante 1 hora. Para la tinción de AP, las células fueron fijadas con citrato-acetona-formaldehído 37\%, lavadas con agua desionizada y coloreadas con sal de diazonio 
compuesta por solución de nitrito sódico $0.1 \mathrm{~mol} / \mathrm{L}$ (Sigma-Aldrich), solución FRV alcalina Base de Fast Red Violet LB 5 mg/mL (Sigma-Aldrich) y solución de naftol AS-BI fosfato $4 \mathrm{mg} / \mathrm{mL}$ (Sigma-Aldrich). La contratinción se llevó a cabo con solución de hematoxilina de Gill N’3 (Sigma-Aldrich). Las células fueron observadas bajo microscopio invertido.

\section{Resultados \\ Población de estudio}

Doce pacientes con edad promedio de 35,2 años (entre los 19 y 60 años), 75\% mujeres y 25\% hombres, se sometieron a cirugías de liposucción convencional o por ultrasonido (VASER'), y aceptaron participar libremente mediante firma del consentimiento informado para donar el tejido adiposo.

\section{Obtención y procesamiento de las células de tejido adiposo}

A partir de la digestión enzimática con Colagenasa Tipo I se obtuvo un promedio de $6,93 \times 10^{5}$ células nucleadas por gramo de grasa y una media de viabilidad del $92 \%$.

La criopreservación de las células de la fracción 1 se realizó a una densidad de $1 \times 10^{6}$ células nucleadas $/ \mathrm{mL}$, con las soluciones A y B. Una vez descongeladas, las células fueron sembradas a una densidad de $1 \times 10^{6}$ células nucleadas $/ \mathrm{cm}^{2}$, obteniendo para ambos casos una media de tiempo de 25 días para alcanzar confluencia del $80 \%$ en el primer pase cultivo, con una media de $5.23 \times 10^{5}$ células para la solución A y $5.22 \times 10^{5}$ células para la solución B, Tabla 1, Figura 2 .

Tabla 1. Comparación de viabilidad con las dos soluciones de congelamiento.

\begin{tabular}{ccc} 
PARÁMETRO & & PROMEDIO \\
\cline { 2 - 3 } & FRACCIÓN 1 & FRACCIÓN 2 \\
Células nucleadas solución A & $5.23 \times 10^{5}$ células & $6 \times 10^{5}$ células \\
Viabilidad solución A & $34 \%$ & $62 \%$ \\
Células nucleadas solución B & $5.22 \times 10^{5}$ células & $6 \times 10^{5}$ células \\
Viabilidad solución B & $25 \%$ & $35 \%$ \\
\hline
\end{tabular}

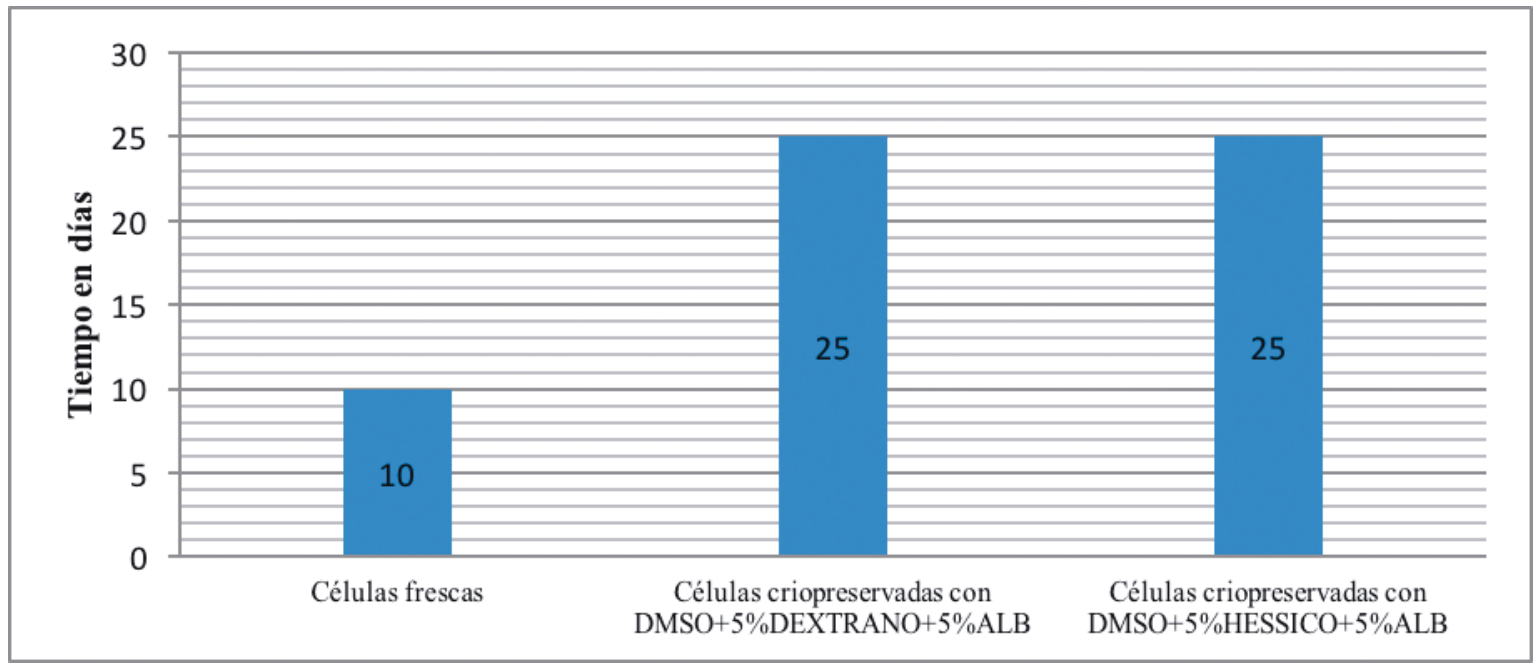

Figura 2. Tiempo transcurrido para alcanzar confluencia de $80 \%$ en células frescas y células criopreservadas de la fracción 1. 
De la misma forma, el cultivo de las células de la fracción 2 antes de la criopreservación se realizó a una densidad de $1 \times 10^{6}$ células nucleadas $/ \mathrm{cm}^{2}$, obteniendo una media de tiempo de 10 días para obtener confluencia del $80 \%$ en el primer pase de cultivo, y una media de $9,5 \times 10^{5}$ células. En la figura 3 se observa el registro morfológico mediante microscopía invertida de las células con aspecto fibroblastoide, cultivadas con DMEM-LG suplementado con $10 \%$ de LPRP a diferentes tiempos.
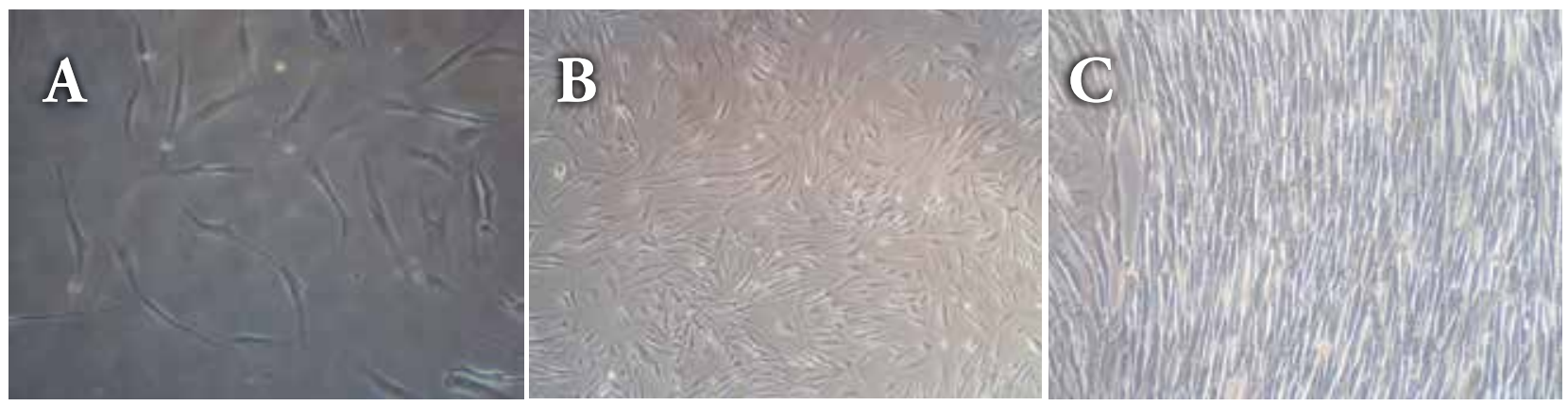

Figura. 3. Cultivo de ADAS. A) Células adherentes fibroblastoides después de un día de cultivo (20X). B) Células adherentes fibroblastoides con morfología homogénea después de 6 días de cultivo (10X). C) Células después de 10 días de cultivo (10X).

Después de la criopreservación, las células de la fracción 2 mostraron promedios de tiempo mejores, con una media de 6 días para alcanzar confluencia de $80 \%$ en el segundo pase de cultivo para las células criopreservadas con la solución A y media de tiempo de 9 días para las células criopreservadas con la solución B, Figura 4.

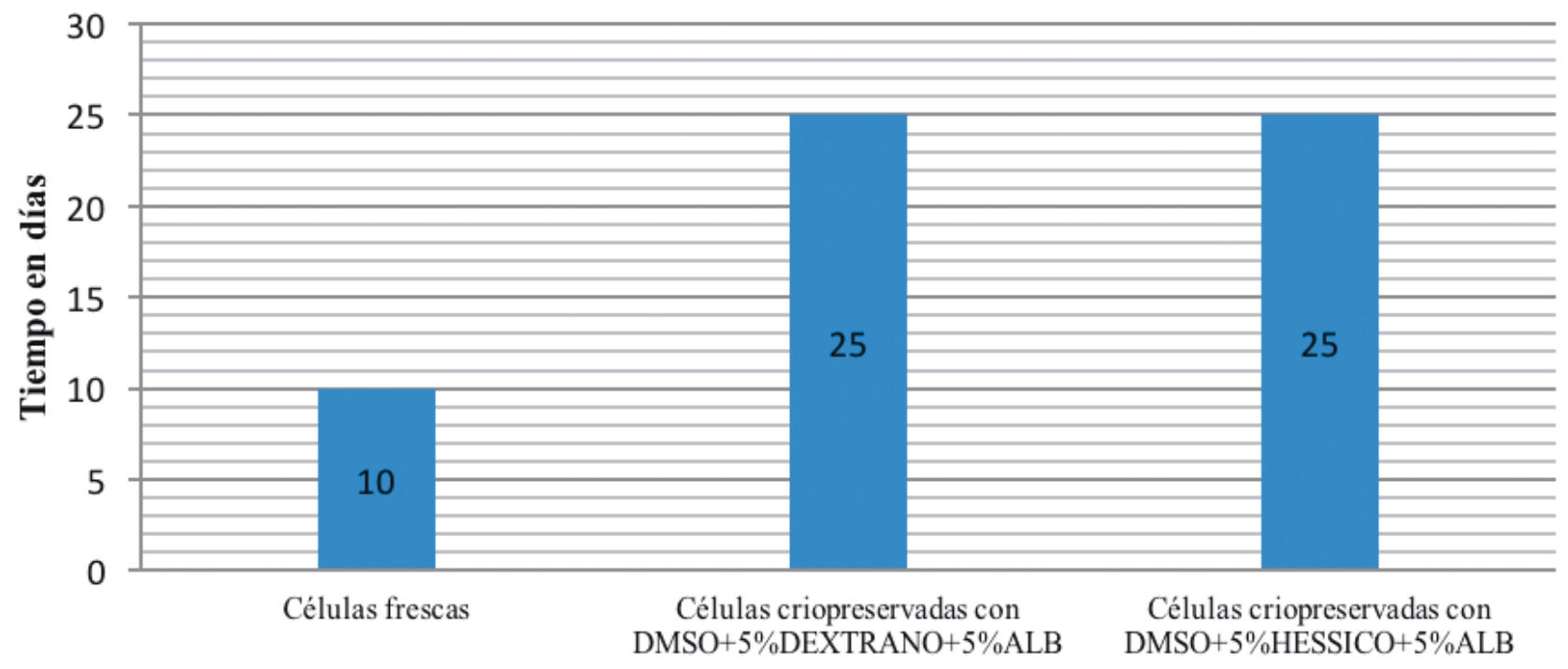

Figura. 4. Tiempo transcurrido para alcanzar confluencia de $80 \%$ en células frescas y células criopreservadas de la fracción 2. 
Los porcentajes de viabilidad pos descongelamiento para ambos grupos de células criopreservadas con las dos combinaciones de ACP se pueden observar en la Figura 5. La media del porcentaje de pérdida de viabilidad con respecto a la viabilidad antes del congelamiento para las células de la fracción 1 criopreservadas con DMSO/Dextrano40/HSA fue del 58\%, para las células de la misma fracción criopreservadas con DMSO/HESSICO/HSA fue del 67\%, siendo este el más alto entre los 4 grupos de células. Para las células de la fracción 2 criopreservadas con DMSO/ Dextrano40/HSA la media del porcentaje de pérdida de viabilidad fue del 30\%, siendo este el más bajo entre los 4 grupos de células criopreservadas, y para las células de la misma fracción criopreservadas con DMSO/HESSICO/HSA fue del 57\%.

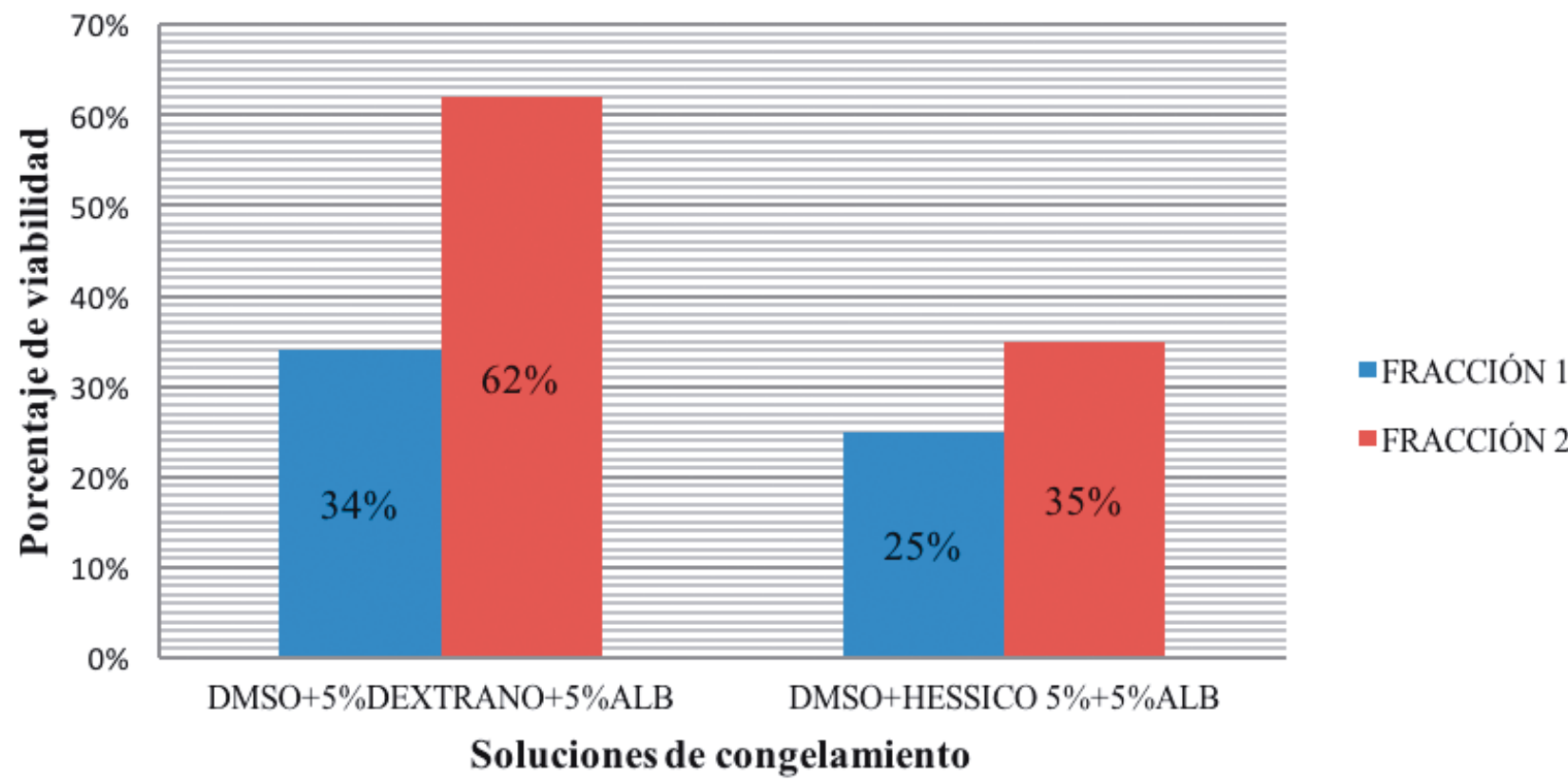

Figura. 5. Comparación de la viabilidad de células madre criopreservadas.

\section{Fenotipificación}

El fenotipo de las MSC se determinó por citometría de flujo evaluando la expresión de los antígenos de superficie CD90, CD105 y CD73 característicos de MSC, junto con el antígeno CD44, marcador de superficie celular que también puede ser expresado por este tipo de células. Se usaron como control células sin marcar. Los resultados de la citometría de flujo para las células mesenquimales obtenidas de tejido adiposo se observan en la Figura 6, siendo positivas para los marcadores CD90 y CD73, con una expresión menor de CD105, y negativas para los marcadores CD11b, CD19, CD34, CD45, HLA-DR. Este inmunofenotipo coincide con los parámetros determinados por la International Society for Cellular Therapy (ISCT) como el perfil característico de las células madre mesenquimales (12). Las células expandidas pre y post congelamiento no presentaron diferencias en el fenotipo. 


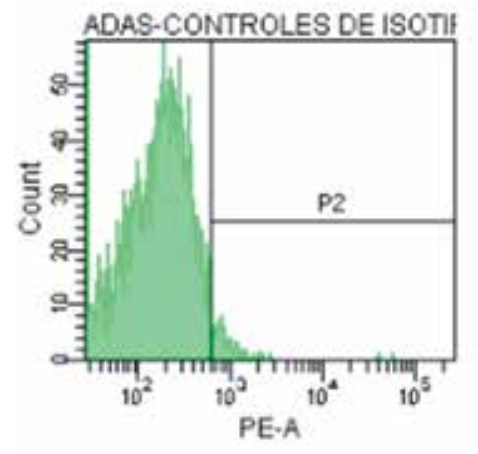

A
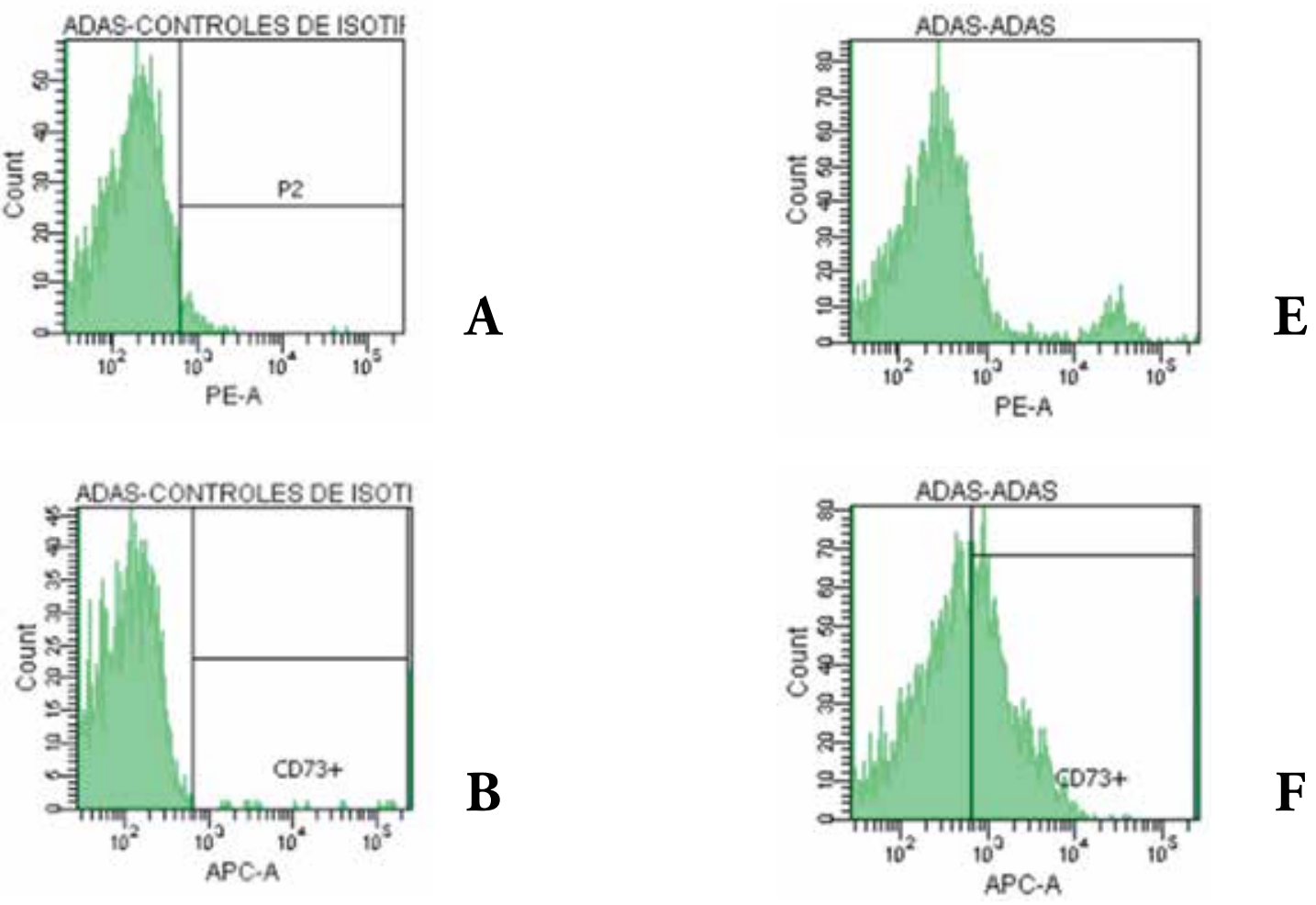

$\mathbf{F}$
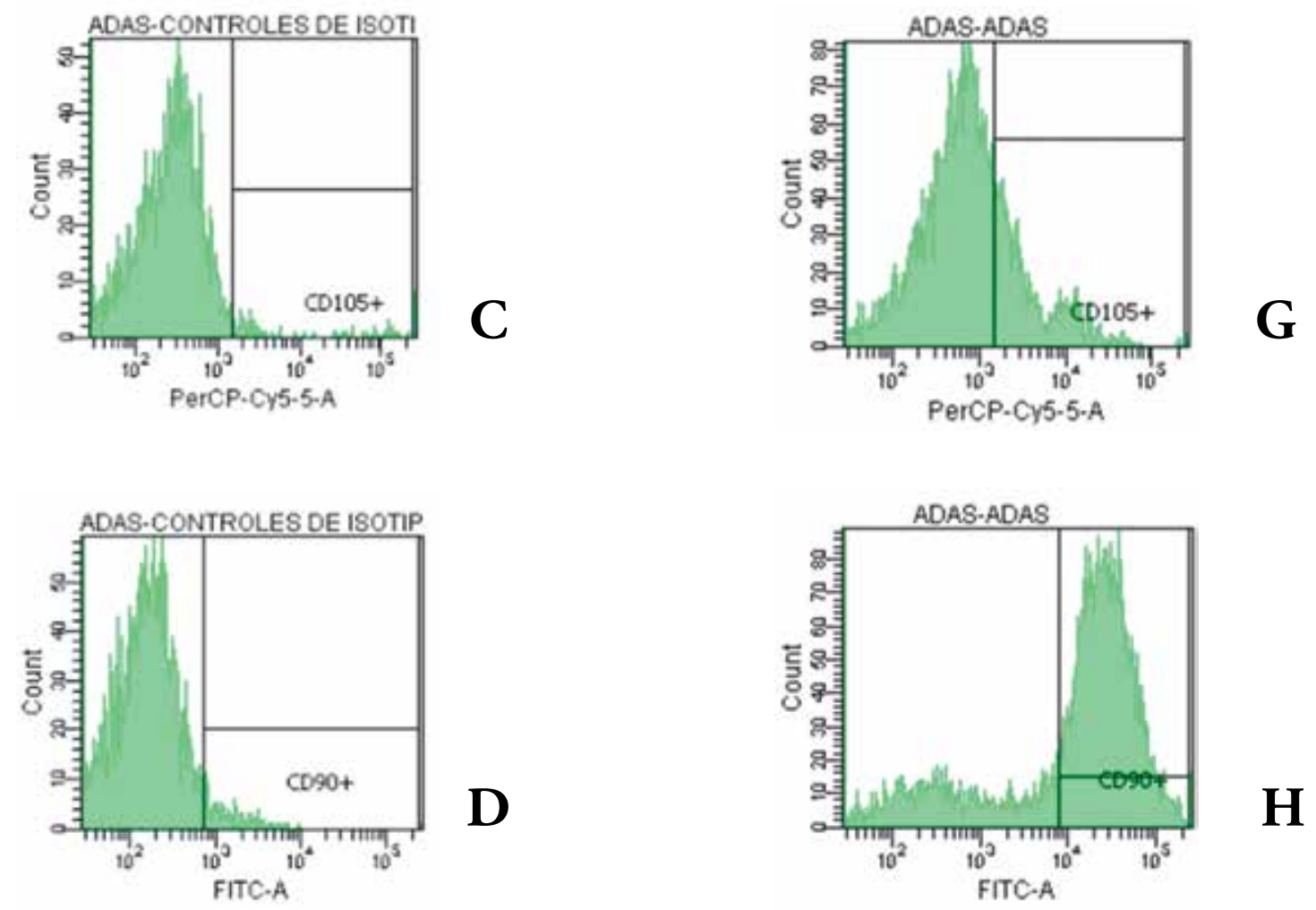

Figura 6. Inmunofenotipo de células madre mesenquimales obtenidas de tejido adiposo mediante citometria de flujo en segundo pase de cultivo pos descongelamiento. En la columna de la izquierda (A, B, C, D) se pueden observar los controles de isotipo para cada uno de los marcadores. En la columna de la derecha las MSCs. E. Células marcadas con CD45/CD34/CD11b/CD19/HLA-DR PE. F. Células marcadas con CD73 APC. G. Células marcadas con CD105 PerCP-Cy ${ }^{\mathrm{TM}}$ 5.5. H. Células marcadas con CD90 FITC. 


\section{Diferenciación osteogénica}

Las células expandidas pre y post congelamiento se diferenciaron a linaje osteogénico, demostrado mediante tinción de Von Kossa para depósitos de calcio y tinción histoquímica para determinar la actividad de la enzima AP, en células ADAS a las 5 semanas de cultivo de inducción in vitro, Figura 7.
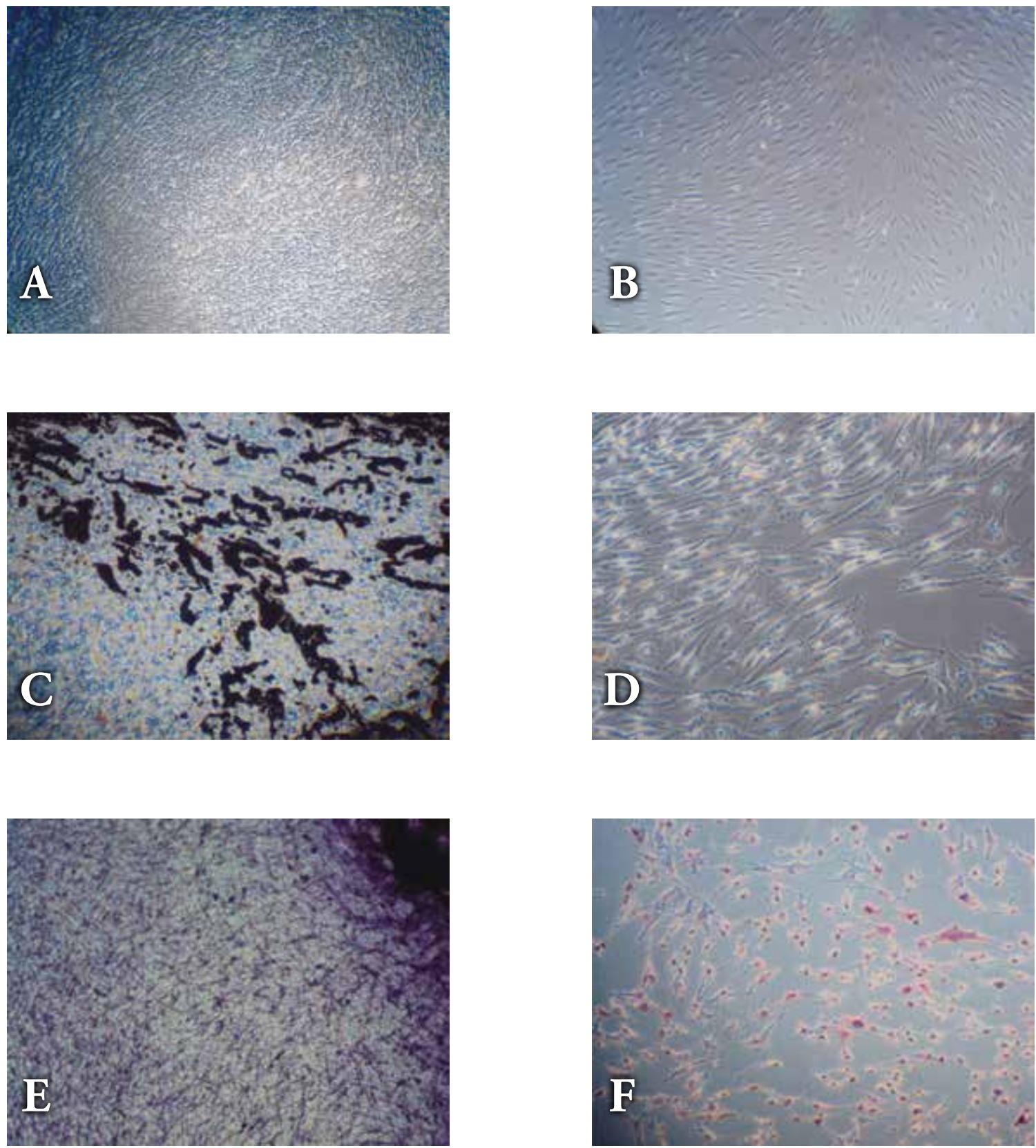

Figura 7. Diferenciación osteogénica. A) Células bajo inducción osteogénica día 15. B) Células control con DMEM. C) Tinción de Von Kossa para depósitos de calcio en células ADAS a las 5 semanas de inducción. D). Tinción de Von Kossa en células control. E) Tinción histoquímica de AP en ADAS después de 5 semanas de inducción. F) Tinción histoquímica de AP en células control. Magnificación $10 \mathrm{X}$ en todas las imágenes. 


\section{Discusión}

El tejido adiposo es una fuente apropiada para la obtención de células madre mesenquimales teniendo en cuenta la facilidad de obtención y la cantidad de células aisladas en comparación con otras fuentes (13). En este estudio confirmamos que es posible obtener un promedio de $6,93 \times 10^{5}$ células nucleadas por gramo de grasa con una media de viabilidad mayor al $90 \%$, resultados comparables con los obtenidos en trabajos anteriores en los que el promedio de células fue del $7 \times 10^{5}$ células por gramo de grasa (14).

En la literatura se encuentra reportado el precultivo para la crioconservación de especies de semillas vegetales mediante técnicas de vitrificación y deshidratación (15), resultando efectivo para mejorar la sobrevivencia después del almacenamiento, gracias a la acumulación de azúcares que aumentan la deshidratación protectora de los tejidos a congelar y la concentración de solutos a nivel interno, mejorando también la estabilidad de las membranas bajo condiciones severas de deshidratación (16). Sin embargo, no hay mucha información sobre la aplicación de esta misma técnica con otro tipo de material biológico como es el caso de las células madre.

En cuanto al cultivo celular primario, Arévalo P. y Páez D. reportaron que existe contaminación con progenitores hematopoyéticos al día 10 de cultivo, demostrado con la expresión positiva para CD34 y CD45 en la fenotipificación por cartometría de flujo de MSCs de sangre de cordón umbilical (SCU) y médula ósea (MO), expresión que varía al realizar el primer pase de cultivo, en donde disminuye la expresión de estos marcadores, lo que indica que al realizar pases de cultivo se purifica la población de MSC (17).

De forma similar, en el presente trabajo se encontró de forma importante que la criopreservación de las MSC no afecta su capacidad proliferativa, sin embargo el rendimiento mejora si se realiza un cultivo previo al congelamiento. Consecuentemente, las células de la fracción 2 con precultivo mostraron medias de viabilidad y de cantidad células recuperadas más altas que las células de la fracción uno sin precultivo. Del mismo modo, los tiempos para alcanzar confluencia del $80 \%$ fueron comparables entre las células frescas y las células de la fracción dos criopreservadas. No así las células de la fracción uno criopreservadas con ambas soluciones que requirieron más tiempo de proliferación hasta alcanzar la misma confluencia.

Es importante resaltar que la diferencia entre las dos soluciones de congelamiento radicó en el ACP no penetrante, el cual ejerce su acción crioprotectora promoviendo la rápida deshidratación celular, y se usa asociado al DMSO (ACP penetrante) (7). De las soluciones de congelamiento evaluadas en este estudio, la solución A compuesta por DMSO/ Dextrano40/HSA permitió mayores porcentajes de viabilidad pos descongelamiento con una media de viabilidad del $62 \%$ para las células con precultivo, siendo este el mayor porcentaje entre los grupos evaluados. No obstante, las células sin precultivo presentaron porcentajes de viabilidad más bajos a pesar de ser congeladas con la misma solución A, lo que también ratifica la importancia de un cultivo previo al congelamiento. La solución B compuesta por DMSO/HESSICO/HSA, mostró los valores más bajos con respecto a viabilidad en los dos casos (con y sin precultivo).

En este estudio las células en cultivo mostraron adherencia al plástico y morfología fibroblastoide, y se demostró la presencia de los marcadores CD73 y CD90, mientras que la presencia del antígeno CD105 se observó en un porcentaje más bajo, coincidiendo con estudios realizados previamente con MSC de médula ósea, en los que se presenta un índice medio de flourescencia bajo, razón por la cual se está considerando que no es un antígeno que deba incluirse para determinar el fenotipo de MSC, ya que no determinan e identifican a esta población celular (18). 
De la misma forma, estudios más recientes han demostrado que los componentes del medio de cultivo pueden afectar la expresión de proteínas de superficie, tal es el caso de los medios sin suero donde se observa que las células cultivadas presentan una disminución en la expresión del antígeno CD105 en comparación con las células expandidas en presencia de suero (19). Cabe resaltar que los medios de cultivo empleados en este estudio no contenían suero fetal bovino, debido a que este suplemento fue reemplazado por lisado de plasma rico en plaquetas, lo que lleva a pensar que la sustitución del suplemento puede estar relacionada con la baja expresión del marcador de superficie CD105, tal y como lo han descrito Mark P. y colaboradores.

Así mismo, las células evaluadas fueron negativas para los marcadores CD11b, CD19, CD34, CD45, HLA-DR. Este perfil de expresión coincide con el perfil de marcadores de superficie celular descrito típicamente para las células madre mesenquimales en la literatura (20) Además, se demostró que estas células son capaces de diferenciarse hacia el linaje osteogénico cumpliendo con los parámetros internacionales para ser definidas como células madre mesenquimales (12).

El trabajo de investigación de Muñoz C.M, había demostrado que del tejido adiposo obtenido por método de liposucción convencional se podía aislar una mayor cantidad de células por gramo de grasa en comparación con las muestras obtenidas de liposucción por ultrasonido (VASER ${ }^{\circ}$ ), sin embargo, ambos métodos arrojaron resultados de viabilidad y tiempo de confluencia similares, sin diferencias fenotípicas entre las células obtenidas por los dos métodos de liposucción (14). Por esta razón, las muestras obtenidas para este trabajo no se clasificaron teniendo en cuenta el método de liposucción.

Este estudio aporta información sobre la combinación de agentes crioprotectores para el congelamiento de células madre mesenquimales obtenidas de tejido adiposo, sugiriendo que la solución crioprotectora ideal para la criopreservación de ADAS es la conformada por DMSO/Dextrano40/HSA, combinada con un cultivo previo al congelamiento para aumentar el porcentaje de viabilidad de las células. Las 2 fracciones de ADAS conservan fenotipo y capacidad de diferenciación a linaje osteogénico posterior al descongelamiento.

\section{Agradecimientos}

Al personal de enfermería del área de cirugía plástica de la Clínica Sabamec en Bogotá, por la recolección de las muestras de tejido adiposo.

\section{Referencias}

1. Gimble, J.M., Guilak, F. Adipose-derived adult stem cells: Isolation, characterization, and differentiation potential. Cytotherapy. 2003; 5 (5): 362-369.

2. Jezierska-Wozniak K, Nosarzewska D, Tutas A, Mikolajczyk A, Oklinski MK.: Use of adipose tissue as a source of mesenchymal stem cells. Postepy Hig Med Dosw (online). 2010; 27(64):326.

3. Patricia A. Zuk et al. Human Adipose Tissue Is a Source of Multipotent Stem Cells. Molecular Biology of the Cell. 2002; 13(12):4279-4295.

4. Pineda Molina C, Londoño Peláez C. Obtención de células madre del tejido adiposo y su potencial de diferenciación osteogénico. Rev Ing Bioméd. 2009; 3(5): 58-65.

5. Strem BM et al. Multipotential differentiation of adipose tissue-derived stem cells. Keio J Med. 2005; 54(3):132-41.

6. Planas Ribó, J., Coronel Gagliardi, R. Obtención y criopreservación de células madre del tejido graso mediante liposucción. Cir.plást. iberolatinoam. 2011; 37(4):319- 324.

7. Ávila-Portillo, L. M., Madero, J. I., López, C., León, M. F., Acosta, L., Gómez, C., Delgado, L. G., Gómez, C. J., Lozano, M., Reguero, M. T. Fundamentos de Criopreservación. Revista Colombiana de Obstetricia y Ginecología.2006; 57 (4): 291-300.

8. Sreedhar Thirumala, Jeffrey M. Gimble, Ram V. Evaluation of Methylcellulose and Dimethyl Sulfoxide as the Cryoprotectants in a Serum Free Freezing Media for Cryopreservation of Adipose-Derived Adult Stem Cells. Devireddy Stem Cells Dev. 20101; 19(4): 513-522.

9. Rodríguez G. L. Reconstitución de productos hematopoyéticos criopreservados: control de calidad, estabilidad osmótica y lavado de DMSO. Universidad Autónoma de Barcelona. Trabajo de Tesis.

10. Complexo Hospitalario Universitario de Santiago. Servicio de Farmacología Clínica. Expansores plasmáticos. Boletín de información terapéutica. 2002; 1:13. 
11. Lee L.Q. Pu. Cryopreservation of adipose tissue. Organogenesis.2009; 5(3): 138-142.

12. Dominici M, Le Blanc K, Mueller I, et al. Minimal criteria for defining multipotent mesenchymal stromal cells. The International Society for Cellular Therapy position statement. Cytotherapy. 2006; 8(4):315-317.

13. Peng, L., Jia, Z., Yin, X., Zhang, X., Liu, Y., Chen, P., \& Zhou, C. Comparative analysis of mesenchymal stem cells from bone marrow, cartilage, and adipose tissue. Stem cells and development. 2008; 17(4): 761-774.

14. Muñoz C.M. Comparación del número viable y fenotipo de células madre mesenquimales de tejido adiposo por método de liposucción convencional y método de liposucción por ultrasonido (Vaser"). [Trabajo de grado]. Colombia (BOG): Pontificia Universidad Javeriana; 2009.

15. García T. y Abdelnour A. Crioconservación de Ápices y semillas de cedro (Cedrela odorata L.) mediante las técnicas de vitrificación y deshidratación. Agron. Costarricense [online]. 2013;37: 113-126.

16. Takagi H. Recent developments in cryopreservation of shoot apices of tropical species, Cryopreservation of Tropical Germplasm Current Research Progress and Application. IPGRI. Rome, Italy. 2000: 178-191, citado por García T. y Abdelnour A. Crioconservación de Ápices y semillas de cedro (Cedrela odorata L.) mediante las técnicas de vitrificación y deshidratación. Agron. Costarricense [online]. 2013;37(1):113-126.

17. Arévalo J. y Paéz D. Cultivo de células madre mesenquimales a partir de sangre de cordón umbilical y médula ósea [Trabajo de grado]. Colombia (BOG): Pontificia Universidad Javeriana; 2007:88p.

18. Fuentes Lacouture MF. Optimización del sistema de cultivo y caracterización de células madre mesenquimales obtenidas a partir de médula ósea humana [Trabajo de grado]. Colombia (BOG): Pontificia Universidad Javeriana; 2008. 83 p.

19. Peter Mark, Mandy Kleinsorge, Ralf Gaebel, et al., "Human Mesenchymal Stem Cells Display Reduced Expression of CD105 after Culture in Serum-Free Medium," Stem Cells International, 2013, Article ID 698076, 8 pages, 2013. doi:10.1155/2013/698076

20. Linero I. M., Doncel A., Chaparro O. Proliferación y diferenciación osteogénica de células madre mesenquimales en hidrogeles de plasma sanguíneo humano. Biomédica. 2014; 34:67-78. 